Disponível em

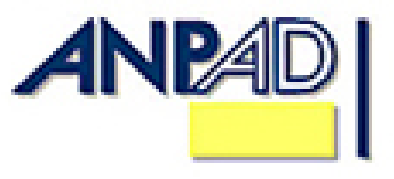
http://www.anpad.org.br/rac

RAC, Rio de Janeiro, v. 18, n. 1, art. 2, pp. 20-36, Jan./Fev. 2014

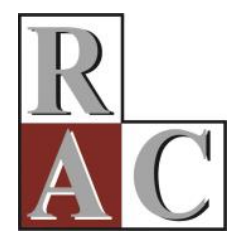

\title{
Processo de Institucionalização do Curso de Administração Pública a Distância em uma Universidade Federal
}

\section{Institutionalization Process of a Distance Public Administration Course of a Federal University}

\author{
Rosália Rodrigues Alves \\ E-mail: rosaliaadm@gmail.com \\ Universidade Federal de Lavras - UFLA \\ DAE/UFLA, Caixa Postal 3037, 37200-000, Lavras, MG, Brasil. \\ Cleber Carvalho de Castro \\ E-mail: clebercastro@dae.ufla.br \\ Universidade Federal de Lavras - UFLA \\ DAE/UFLA, Caixa Postal 3037, 37200-000, Lavras, MG, Brasil. \\ Cleverton Luiz Souto \\ E-mail: clsadmufla@ymail.com \\ Universidade Federal de Lavras - UFLA \\ DAE/UFLA, Caixa Postal 3037, 37200-000, Lavras, MG, Brasil.
}




\title{
Resumo
}

Este trabalho objetivou analisar o processo de institucionalização do curso de graduação em administração pública a distância da Universidade Federal de Lavras e, especificamente, analisar as fases do processo de institucionalização e identificar evidências de isomorfismo e legitimação. Para tanto, o estudo baseia-se na teoria de Tolbert e Zucker (1998) que subdivide o processo de institucionalização em três distintas fases: habitualização, objetificação e sedimentação. Para a coleta de dados, realizaram-se entrevistas semiestruturadas com os coordenadores do curso, do Centro de Educação a Distância e do departamento de Administração e Economia, totalizando 11 entrevistas. Essas foram gravadas e transcritas. Após a transcrição, realizou-se análise de conteúdo temática com o apoio do software livre Weft QDA (Qualitative Data Analysis). De uma forma geral, pode-se perceber que está ocorrendo o processo de institucionalização do curso de administração pública a distância, apresentando um estágio moderado de habitualização e objetificação, e um estágio de baixa sedimentação. Nesse processo, evidenciaram-se o isomorfismo coercitivo e a legitimidade regulativa.

Palavras-chave: processo de institucionalização; administração pública; educação a distância.

\begin{abstract}
The objective of this study was to analyze the institutionalization process of an online graduate course in public administration at the Federal University of Lavras (Universidade Federal de Lavras [UFLA]), specifically the institutionalization process phases, and to identify evidence of isomorphism and legitimacy. The study is based on Tolbert and Zucker's theory (1998) which subdivides the institutionalization process into three distinct phases: habitualization, objectification and sedimentation. Using a qualitative perspective, semi-structured interviews were conducted with course coordinators of the Distance Education Center and the Management and Economy Department, totaling 11 interviews. These were recorded and transcribed. After the transcript was subjected to thematic content analysis using Weft QDA (Qualitative Data Analysis). In general, the institutionalization process of the online public administration course is characterized by a moderate stage of habitualization and objectification and a low stage sedimentation. Coercive isomorphism and regulative legitimacy was also evident.
\end{abstract}

Key words: institutionalization process; public administration; distance education. 


\section{Introdução}

O ensino superior brasileiro vive um cenário de expansão desde o início do século XXI. Em 2001, havia 3.036.113 matriculados no ensino superior e, em 2010, esse número mais que duplica, somando 6.379.299. Essa ampliação pode ser consequência do crescimento econômico do país, que tem como obstáculo a falta de mão de obra qualificada nos diversos setores. A demanda por mão de obra pode ter gerado o aquecimento na oferta de ensino superior. Outro fator pode ser a proposta de democratização do ensino do Plano Nacional de Educação 2001-2010, em que o governo implementou algumas políticas públicas para acelerar o crescimento da educação superior, como é o caso do Programa Universidade para Todos (PROUNI), que objetiva conceder bolsas de estudo integrais e parciais, e o Fundo de Financiamento Estudantil (FIES) que é destinado a financiar a graduação de alunos matriculados em instituições que não são gratuitas.

As instituições federais, por sua vez, contam com o Programa de Apoio aos Planos de Reestruturação e Expansão das Universidades Federais (Reuni), que busca expandir, ampliar, interiorizar e consolidar a rede de institutos e universidades federais, democratizando e ampliando o acesso de vagas em educação profissional, tecnológica e superior.

A criação do Sistema Universidade Aberta do Brasil (UAB) surge, também, nesse cenário expansionista. Esse sistema é integrado por universidades públicas que oferecem curso superior para camadas da população que ainda têm dificuldade de acesso a esse ensino, por meio da modalidade a distância. O crescimento dessa modalidade é tão expressivo que em 2010 correspondia a 14,6\% do total de matriculados no ensino superior, o que justifica a escolha da graduação a distância como objeto de estudo.

Dentre as possibilidades teóricas de análise, optou-se pelo uso da Teoria Institucional. Essa teoria possibilita analisar todo o processo de implementação e de oferta dessa modalidade de ensino, como sendo um novo arranjo organizacional dentro das universidades, bem como as pressões existentes para essa oferta e a existência de grupos opositores e defensores. De uma forma geral, a teoria institucional possibilita analisar se a educação a distância é uma estrutura que está ou não se consolidando, e como as universidades estão trabalhando com esse novo arranjo (Tolbert \& Zucker, 1998), ou seja, se está se institucionalizando. A utilização dessa teoria também se justifica pelo fato de ainda existirem poucos trabalhos que fazem a ligação entre a teoria institucional e a educação a distância.

Novais e Fernandes (2011), por exemplo, buscaram descrever como estava ocorrendo o processo de institucionalização do curso a distância, mas utilizou como objeto de estudo o curso de administração do projeto piloto da Universidade Federal do Rio Grande do Norte (UFRN). O projeto piloto analisado iniciou-se em 2006 com data limite em 2010, em uma iniciativa do Ministério da Educação (MEC), Universidade Aberta do Brasil e Banco do Brasil. O fato de o projeto piloto ter data para ser finalizado e ser uma única oferta pode diferenciar, de forma significativa, o processo de institucionalização.

A institucionalização não consiste em um dueto de ser ou não ser, e sim uma questão de grau (Owen-Smith, 2011). Assim, o ensino superior na modalidade a distância nas universidades pode estar em um maior ou menor grau de institucionalização.

Dentro do Sistema UAB está o Programa Nacional de Formação em Administração Pública (PNAP) que tem por objetivo geral formar profissionais com amplo conhecimento em administração pública, capazes de atuar no âmbito federal, estadual e municipal, administrando com competência e ética as organizações governamentais e não governamentais. Esse estudo foca o curso de graduação em administração pública, integrante do PNAP, oferecido pela UAB por meio da Universidade Federal de Lavras. O objetivo geral foi analisar o processo de institucionalização do curso de graduação em administração pública a distância da Universidade Federal de Lavras, e, especificamente, analisar as fases do processo de institucionalização e identificar evidências de isomorfismo e legitimação. 


\section{Referencial Teórico}

O referencial teórico inicia-se apresentando brevemente a teoria institucional, e os conceitos de institucionalização, isomorfismo e legitimidade a partir das visões dos autores selecionados. Apresenta-se de forma mais detalhada o processo de institucionalização de Tolbert e Zucker (1998) por ser base para o estudo. Posteriormente, apresenta-se a realidade da educação a distância no Brasil.

\section{Teoria institucional}

A teoria institucional vem sendo utilizada de forma crescente como base para estudos empíricos, desde o final da década de 1980 (Carvalho, Vieira, \& Goulart, 2005). Essa abordagem tem sido usada em três distintas vertentes: econômica, política e sociológica, destacando conceitos como institucionalização, legitimidade, mitos e normas (Carvalho, Vieira, \& Lopes, 1999).

As análises nos campos de estudos organizacionais através da perspectiva institucional são crescentes, quantitativa e qualitativamente (Machado-da-Silva, Guarido, Nascimento, \& Oliveira, 2003). Essa teoria se tornou dominante nos estudos dos fenômenos macro-organizacionais (Suddaby, 2010). A vertente sociológica, base para este estudo, analisa as relações organização-ambiente inicialmente focadas nas interações informais, relações de poder e no processo constitutivo das instituições, que posteriormente se evidenciam a conformidade, a legitimação e a homogeneidade entre as organizações (Carvalho et al., 2005).

A conformidade foi estudada por alguns ícones da teoria institucional como, por exemplo, DiMaggio e Powell, em 1983. Em seus trabalhos, os autores buscaram descrever porque existe homogeneidade de formas e práticas organizacionais dentro de um campo organizacional. De acordo com esses autores, o ambiente é um fator de homogeneização organizacional na medida em que práticas e formas de organização institucionalizadas são difundidas pela comunidade de agentes de um mesmo campo.

O processo de homogeneização é chamado de isomorfismo. O isomorfismo pode ser competitivo ou institucional. O foco da teoria institucional é dado no isomorfismo institucional. Dentro desse, existem três tipos de mecanismos isomórficos, a saber, que podem coexistir no contexto empírico, embora apresentando resultados e origens diversos: isomorfismo coercitivo, isomorfismo mimético e isomorfismo normativo (Dimaggio \& Powell, 1983).

O isomorfismo coercitivo resulta de pressões formais assim como de pressões informais exercidas sobre as organizações. Essas pressões, geralmente, são exercidas por organizações das quais dependem, e pelas expectativas culturais da sociedade. Em algumas situações, uma mudança organizacional pode ser ocasionada mediante uma resposta a ordens governamentais. É derivada, então, de uma autoridade coercitiva. A base desse processo isomórfico é realista social (Machado-daSilva et al., 2003).

O isomorfismo mimético é uma resposta da organização às incertezas do mercado. A incerteza encoraja a imitação. Nem sempre a organização imitada tem consciência, ou gostaria de ser imitada. As organizações tomam como modelo organizações que percebem ser mais legítimas ou bem sucedidas (Dimaggio \& Powell, 1983).

As pressões normativas são a terceira fonte das mudanças isomórficas nas organizações (Dimaggio \& Powell, 1983). Essa pressão deriva do profissionalismo. Universidades, instituições de treinamento técnico, associações profissionais e de investigação são veículos para o desenvolvimento e a divulgação de regras normativas.

A legitimação, por sua vez, foi estudada por Scott (2001), que a reconhece como sendo o objetivo principal da institucionalização. Advoga sobre a legitimidade nos três pilares das instituições: regulativo, normativo e cognitivo. A base da legitimidade no pilar regulativo é a conformidade às 
exigências legais. Nesse pilar, uma organização legitimada é aquela que é estabelecida e opera em conformidade com os requisitos legais. Já a concepção normativa enfatiza uma profunda base moral, para avaliar a legitimidade. Nesse pilar, uma organização é legitimada de acordo com a sua adesão a normas reconhecidas como padrão de comportamento. E a legitimidade cognitiva é fundamentada na noção de compartilhamento. A visão cognitiva enfatiza a legitimidade que vem de um padrão comum de referência.

A institucionalização foi estudada por diversos autores, como Selznick (1971), Berger e Luckmann (1967), Meyer e Rowan (1977), que estão entre os clássicos mais citados. Berger e Luckmann (1967) foram seguidos por Zucker (1977) e Meyer e Rowan (1977). Esses autores se assemelham ao entender a institucionalização como um processo social pelo qual os indivíduos passam a aceitar uma definição comum da realidade social, uma definição de como as coisas são ou deveriam ser (Scott, 1987).

De acordo com Green, Li e Nohria (2009), a institucionalização, como um estado, é incorporada no argumento para justificar a prática em um determinado ponto, e, como um processo, é incorporada na estrutura dos argumentos utilizados para justificar uma prática ao longo do tempo. Baptista (2009) possui uma visão distinta de institucionalização como sendo a incorporação gradual da tecnologia nos hábitos e rotinas dos colaboradores de uma organização. A institucionalização pode ocorrer através de interação intensiva e requerer muito tempo, mas também pode ocorrer rapidamente e com pouca interação social (Levine \& Zajac, 2008).

Tolbert e Zucker (1998), vendo a necessidade de um esclarecimento dos processos de institucionalização, propõem um modelo dividido em três fases, o qual é base para esse estudo: habitualização, objetificação e sedimentação. A primeira fase, processo de habitualização, inicia-se com a adoção de novos arranjos estruturais. A organização, geralmente, adota essa nova estrutura em resposta a problemas ou a conjuntos de problemas organizacionais específicos. Nesse estágio ocorre, também, a normalização das novas estruturas em políticas e procedimentos da organização, ou um conjunto de organizações que encontrem problemas iguais ou semelhantes. Estes processos resultam em estruturas que podem ser classificadas como um estágio de pré-institucionalização (Tolbert \& Zucker, 1998).

A objetificação envolve o desenvolvimento de um grau de consenso social entre os decisores da organização a respeito do valor da estrutura e da crescente adoção pelas organizações. Esse processo pode ocorrer por meio de dois mecanismos diferentes, embora não necessariamente desvinculados: as organizações podem colher informações diretamente de uma variedade de fontes, ou através da atuação dos champions. Quando uma estrutura já está sendo testada em outras organizações, pode-se avaliar de forma mais precisa os riscos de sua adoção. Nesse caso, o processo é consequência do monitoramento dos competidores e dos esforços para aumentar a competitividade; ou reciclar velhas invenções sociais.

A objetificação e a difusão da estrutura podem ser consequência do trabalho dos champions. Os champions são um conjunto de indivíduos com interesse na estrutura. As estruturas geralmente têm uma história curta. Os adotantes estarão conscientes de sua qualidade não testada e conscientemente monitorarão a acumulação de evidência a respeito da eficácia das estruturas. As estruturas que se encontram nesse estágio estão semi-institucionalizadas (Tolbert \& Zucker, 1998).

A institucionalização total envolve sedimentação, um processo que fundamentalmente se apoia na continuidade da estrutura e, especialmente, na sua sobrevivência, através de gerações de membros da organização. Assim, a total institucionalização da estrutura depende, provavelmente, dos efeitos conjuntos da baixa resistência relativa por parte de grupos de oposição, de promoção e de um apoio cultural contínuo por grupos de defensores e de uma correlação positiva com resultados desejados (Tolbert \& Zucker, 1998). Esse estágio final pode ser considerado como sendo o estágio no qual as práticas adquirem legitimidade (Morril, 2007). 
É importante destacar que o modelo proposto por Tolbert e Zucker (1998) está sujeito a críticas (Dambrin, Lambert, \& Sponem, 2007; Machado-da-Silva, Fonseca, \& Crubellate, 2005). Machado-daSilva, Fonseca e Crubellate (2005), por exemplo, caracterizam essa abordagem como sendo determinística e unidirecional, e propõem processo de institucionalização recursivo, que pressupõe tanto a persistência como a mudança, tanto a autonomia quanto a imersão social. Apesar desta crítica, acredita-se que o formato de apresentação do modelo de Tolbert e Zucker (1998), apresentado em fases, contribui para a construção do questionário, no sentido de linearizar o pensamento. Salientando que o uso da divisão das três fases da institucionalização não pressupõe que o presente estudo conceitua o processo de institucionalização como linear, pelo contrário, veremos que os autores desse trabalho organizam as três fases de institucionalização de modo que esse se apresenta de forma cíclica.

\section{Educação a distância - EaD}

Por mais que pareça um tema recente, a discussão sobre a educação a distância se iniciou no século XIX, e hoje está sendo muito discutida devido à evolução e à expansão dessa modalidade educacional. A evolução da EaD no mundo está relacionada com o desenvolvimento dos meios de comunicação e com a globalização. De modo geral, Moore e Kearsley (2007) diferenciam 5 gerações da educação a distância, em nível mundial, mediada por diferentes tecnologias de comunicação. A expansão da educação a distância, no Brasil, desde meados da década de noventa do século XX (Vilarinho \& Paulino, 2010), dá-se principalmente pela necessidade de democratização do acesso ao ensino superior e pela melhoria da qualidade do ensino básico, por meio da formação de professores (Alonso, 2010).

O governo federal brasileiro está apoiando, incentivando e financiando o desenvolvimento do ensino superior na modalidade a distância. Em 2005, criou a Universidade Aberta do Brasil (UAB), em parceria com a Associação Nacional dos Dirigentes das Instituições Federais de Ensino Superior ANDIFES e Empresas Estatais, no âmbito do Fórum das Estatais pela Educação com foco nas Políticas e a Gestão da Educação Superior, com vistas à expansão da educação superior, no âmbito do Plano de Desenvolvimento da Educação (PDE) (Instituto Nacional de Estudos e Pesquisas Educacionais [INEP], 2011).

Dessa forma, o Brasil encontra-se em uma fase de consolidação da $\mathrm{EaD}$, principalmente no Ensino Superior. O crescimento está próximo de 20\% ao ano (Moran, 2009). Em 2009, os cursos de graduação a distância tiveram um crescimento de 30,4\% quando comparado com os dados de 2008, seguido de aumento de $12,5 \%$ da graduação presencial (INEP, 2010).

De acordo com os dados do INEP (2011), em 2010 os cursos de graduação a distância representavam 14,6\% do total de matrículas em graduação, totalizando 930.179 alunos.

Apresentado os principais conceitos utilizados nesse trabalho, inicia-se a apresentação dos métodos e procedimentos utilizados na pesquisa.

\section{Métodos e Procedimentos}

Para o desenvolvimento do presente estudo, optou-se pelo uso do estudo de caso. A estratégia de pesquisa denominada estudo de caso é utilizada por pesquisadores que procuram responder as questões como e por que certos fenômenos acontecem, quando os limites entre o fenômeno e o contexto não estão claramente definidos, quando se deseja foco sobre um evento contemporâneo e quando não se requer controle sobre o comportamento do evento (Yin, 1994). Neste estudo, focou-se o caso da Universidade Federal de Lavras.

A Universidade Federal de Lavras (UFLA), inicialmente, Escola Superior de Agricultura de Lavras, foi fundada em 1908. Atualmente oferece 16 cursos de bacharelado, 7 licenciaturas, 19 cursos 
de doutorado e 20 de mestrado. O quadro discente é 14.834 estudantes, de graduação e pós-graduação, presencial e a distância (UFLA, 2011). A Universidade tem tradição na oferta de cursos de graduação presencial e iniciou a oferta de graduação a distância em 2006, com o curso piloto em administração, no Departamento de Administração e Economia, financiado pelo Banco do Brasil, formando, em 2011, um total de 252 administradores. Dando continuidade, esse mesmo departamento iniciou o curso de administração pública a distância em 2010, ofertando 250 vagas em 2010 e 250 vagas em 2011. Hoje a universidade oferta, na modalidade a distância, 4 cursos de graduação: administração pública, licenciatura em filosofia, licenciatura em letras-inglês, licenciatura em letras-português.

$\mathrm{Na}$ fase de coleta de dados da pesquisa, foram realizadas entrevistas semiestruturadas com os principais atores envolvidos na implementação e na continuação dos cursos a distância: a pró-reitoria de graduação, coordenação geral do Centro de Educação a Distância (CEAD), coordenação de projetos, coordenação pedagógica, coordenação de tecnologia da comunicação e informação, coordenação de apoio técnico, coordenação do curso, e chefia de departamento.

Foram realizadas 11 entrevistas, no período de julho a novembro de 2011. Foi entrevistado 1 representante de cada coordenação, inclusive os que já não estão em exercício, mas que eram atuantes na época da implementação do curso. As entrevistas tiveram uma duração média de 55 minutos. $\mathrm{O}$ roteiro de entrevista foi composto por um total de 29 questões, abordando cada fase do processo de institucionalização, assim como o isomorfismo e a legitimação. As entrevistas foram gravadas e transcritas. Após a transcrição, realizou-se a análise de conteúdo com apoio do software livre Weft QDA (Qualitative Data Analysis), ferramenta para análise de dados textuais (Martins \& Meirinhos, 2011), a partir de categorias previamente estabelecidas.

Várias técnicas são utilizadas para atingir os significados em dados qualitativos, como Análise de Expressão, Análise de Relações, Análise Temática e Análise de Enunciação (Minayo, 2000). A análise temática normalmente é utilizada para estudar atitudes, valores, crenças e motivações, o que a torna propícia para a análise dos dados desse estudo. A unidade de registro nessa pesquisa é o tema, como explicitado acima. Como regra de enumeração utilizou-se a frequência, em que todas as aparições possuem o mesmo peso, ou seja, têm a mesma importância. E, por fim, para a categorização, ou seja, a junção das unidades de registro em um grupo de elementos com um título comum, utilizouse o critério semântico. As categorias de análise foram criadas a partir da teoria de Tolbert e Zucker que propõe o processo de institucionalização em três fases distintas. Dessa forma, criou-se uma categoria para cada fase do processo de institucionalização - habitualização, objetificação e sedimentação. Foram criadas, também, uma categoria de análise para a legitimação e o isomorfismo, que são conceitos fundamentais no processo de institucionalização. Dentro de cada categoria, criaramse subcategorias de análise em consonância com os construtos de Tolbert e Zucker (1998) e Quinello (2008), conforme apresentado na Tabela 1.

Tabela 1

Categorias Previamente Estabelecidas para a Análise de Conteúdo

\begin{tabular}{|c|c|c|c|}
\hline Categoria & Subcategoria & Descrição & Referências \\
\hline \multirow{4}{*}{ 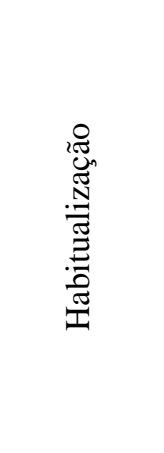 } & Inovação & $\begin{array}{l}\text { Ação que produz modificações fundamentais } \\
\text { causando ruptura ou melhoria contínua em } \\
\text { busca do aperfeiçoamento dos serviços. }\end{array}$ & (Freeman \& Perez, 1988) \\
\hline & Estrutura & $\begin{array}{l}\text { A forma pela qual o trabalho é dividido em } \\
\text { tarefas diferentes e como essas são coordenadas. }\end{array}$ & (Mintzberg, 2003) \\
\hline & $\begin{array}{l}\text { Monitoramento } \\
\text { Interorganizacional }\end{array}$ & $\begin{array}{l}\text { Análise das empresas concorrentes a fim de } \\
\text { buscarem ações legitimadas. }\end{array}$ & (DiMaggio \& Powel, 1983) \\
\hline & $\begin{array}{l}\text { Políticas e } \\
\text { Procedimentos }\end{array}$ & $\begin{array}{l}\text { Os novos arranjos organizacionais adquirem } \\
\text { políticas e procedimentos específicos dentro da } \\
\text { organização. }\end{array}$ & (Tolbert \& Zucker, 1998) \\
\hline
\end{tabular}


Tabela 1 (continuação)

\begin{tabular}{|c|c|c|c|}
\hline Categoria & Subcategoria & Descrição & Referências \\
\hline \multirow{3}{*}{ 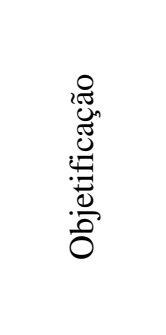 } & Consenso social & $\begin{array}{l}\text { Quanto maior o grau de institucionalização, } \\
\text { menor é a resistência e maior é o consenso } \\
\text { social sobre o valor da estrutura. }\end{array}$ & (Oliver, 1991) \\
\hline & $\begin{array}{l}\text { Difusão da } \\
\text { Estrutura }\end{array}$ & $\begin{array}{l}\text { As formas organizacionais se tornam mais } \\
\text { legítimas quando se espalham. }\end{array}$ & (DiMaggio \& Powel, 1983) \\
\hline & $\begin{array}{l}\text { Presença de } \\
\text { Champions }\end{array}$ & $\begin{array}{l}\text { Um grupo que tem interesse na estrutura pode } \\
\text { promover a sua difusão. }\end{array}$ & (Tolbert \& Zucker, 1998) \\
\hline \multirow{3}{*}{ 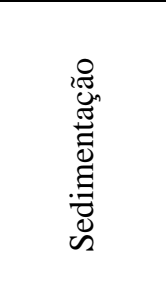 } & $\begin{array}{l}\text { Resultados } \\
\text { positivos }\end{array}$ & $\begin{array}{l}\text { É necessária uma relação positiva entre a } \\
\text { institucionalização e os resultados. }\end{array}$ & (Tolbert \& Zucker, 1998) \\
\hline & $\begin{array}{l}\text { Continuidade da } \\
\text { estrutura }\end{array}$ & Continuidade histórica da estrutura adotada. & (Tolbert \& Zucker, 1998) \\
\hline & Baixa Resistência & $\begin{array}{l}\text { A baixa resistência assegura a perpetuação da } \\
\text { estrutura no tempo. }\end{array}$ & (Zucker, 1988) \\
\hline \multirow{2}{*}{ 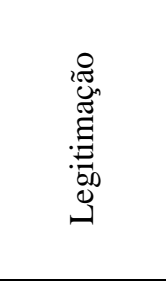 } & $\begin{array}{l}\text { Legitimação } \\
\text { Regulativa }\end{array}$ & $\begin{array}{l}\text { Uma organização legitimada é aquela que é } \\
\text { estabelecida e opera em conformidade com os } \\
\text { requisitos legais. }\end{array}$ & $($ Scott, 2001) \\
\hline & $\begin{array}{l}\text { Legitimação } \\
\text { Normativa }\end{array}$ & $\begin{array}{l}\text { Uma organização é apropriada quando obtém } \\
\text { uma avaliação normativa positiva da sociedade } \\
\text { e de seus stakeholders. }\end{array}$ & $\begin{array}{l}\text { (Rossoni \& Mendes-da- } \\
\text { Silva, 2011) }\end{array}$ \\
\hline \multirow{3}{*}{ 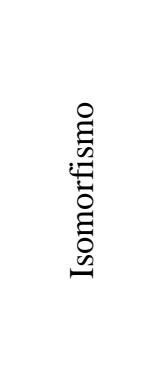 } & $\begin{array}{l}\text { Isomorfismo } \\
\text { Coercitivo }\end{array}$ & $\begin{array}{l}\text { Processo de homogeneização resultante de } \\
\text { pressões formais e informais exercidas sobre as } \\
\text { organizações. }\end{array}$ & (Dimaggio \& Powel, 1983) \\
\hline & $\begin{array}{l}\text { Isomorfismo } \\
\text { Mimético }\end{array}$ & $\begin{array}{l}\text { É uma resposta da organização às incertezas de } \\
\text { mercado, tomando como modelo as } \\
\text { organizações que percebem ser mais legítimas. }\end{array}$ & (Dimaggio \& Powel, 1983) \\
\hline & $\begin{array}{l}\text { Isomorfismo } \\
\text { Normativo }\end{array}$ & $\begin{array}{l}\text { A homogeneização derivada do } \\
\text { profissionalismo. }\end{array}$ & (Dimaggio \& Powel, 1983) \\
\hline
\end{tabular}

\section{Resultados}

Antes de iniciar a descrição do processo de institucionalização, é necessário analisar o contexto histórico do surgimento (Berger \& Luckmann, 2003) do curso de administração pública a distância.

A implementação do curso de Administração Pública a distância na Universidade Federal de Lavras se deu a partir da convergência de 4 fatores. Inicialmente o Departamento de Administração e Economia (DAE) já tinha interesse em implementar o curso de Administração Pública (3 citações), mas ainda não havia sido ofertado por falta de professores da área dentro do quadro de docentes do departamento. A experiência com o curso piloto de administração a distância (5 citações) permitiu que o DAE já tivesse uma experiência com a educação a distância, assim como os professores e a própria universidade. A questão de a universidade estar criando naquele momento o Centro de Educação a Distância (CEAD - 3 citações), um órgão de apoio ao ensino a distância ou semipresencial, e o fato de a Universidade Aberta do Brasil lançar o Programa Nacional de Formação em Administração Pública (PNAP - 7 citações), a fim de formar e qualificar o pessoal de nível superior, visando ao exercício de atividades gerenciais e do Magistério Superior, também foram fatores preponderantes nesse processo. 
Quatro entrevistados não responderam a essa questão, visto que não estavam na coordenação na época da implementação. Apresentado o contexto histórico do surgimento do curso de administração pública a distância na UFLA, parte-se para a análise das categorias elaboradas a partir das fases de institucionalização, assim como para as evidências de isomorfismo e legitimação.

\section{Habitualização}

Dentro da categoria Habitualização, criaram-se três subcategorias: Inovação, Estrutura, Política e Procedimentos. Em se tratando da subcategoria inovação, pode-se perceber que os entrevistados a percebem em diferentes aspectos. A inovação, na opinião dos entrevistados pode ser pela temática administração pública (4 citações), visto que a universidade ainda não tinha esse curso na modalidade presencial. Outro aspecto é o fato de ser um curso de graduação a distância (6 citações) em um novo formato organizacional, criando, por exemplo, o CEAD (4 citações). E somente um entrevistado considerou o curso como não sendo uma inovação pelo fato da universidade já estar envolvida historicamente com educação a distância.

"começar a lidar com uma modalidade nova na graduação, com perfil de público diferente, com necessidade de qualificação específica dos professores, com inserção de elementos novos que são os tutores, os técnicos que trabalham com educação a distância; isso de certa forma é um fator de inovação" (Entrevistado 4).

Nesse sentido, pode-se considerar a implementação do curso de administração pública a distância na UFLA, especificamente no DAE, como sendo uma inovação incremental (Freeman \& Perez, 1988) no produto, assumindo que a universidade já oferece cursos de graduação e cursos na modalidade a distância, passando a ofertar estes agora em um novo formato, exigindo mudanças organizacionais. Para compreender essas mudanças, passa-se a analisar a subcategoria Estrutura, para analisar as adaptações, mudanças que ocorreram na estrutura.

Em relação à estrutura organizacional, o Departamento de Administração e Economia foi acrescido por um colegiado de curso ( 2 citações), começou a atuar conjuntamente com o CEAD, órgão esse que oferece total apoio (11 citações) e o financiamento é externo, via UAB (3 citações), o que de certa forma acarreta em uma mudança organizacional.

Outras mudanças foram percebidas em nível de procedimentos específicos para essa modalidade de ensino. Para isso, parte-se para análise da terceira subcategoria: Políticas e Procedimentos. A universidade criou a resolução CEPE 200, de 27 de julho de 2010, que dispõe sobre as normas gerais para os cursos de graduação a distância (3 citações), pelo fato de cursos dessa modalidade exigirem algumas especificidades que, no regulamento geral de graduação, não estavam previstos.

"é um curso que deveria se inserir dentro das normas da graduação da UFLA, só que tem algumas especificidades, então foi criada até uma resolução CEPE pra contemplar essas especificidades da educação a distância, mas as normas gerais da UFLA, dos Conselhos; teoricamente o curso a distância está inserido também, mas tem algumas especificidades que não" (Entrevistado 6).

Pela ocorrência de citações, quando os entrevistados foram questionados sobre a existência de políticas e procedimentos específicos para a educação a distância, parece que a resolução ainda não é muito divulgada. Outra questão abordada é o fato dessa resolução ser falha por não abordar questões necessárias. Dessa forma, ainda hoje, algumas ações são aprovadas nos conselhos para "apagar incêndio" (Entrevistado 5), mas algumas já se tornaram parte da rotina da universidade.

Outra normalização citada foi a questão específica do professor (3 citações). O professor, geralmente do quadro de docentes da UFLA, que trabalha com ensino no curso de administração pública a distância recebe uma bolsa da UAB/CAPES, como incentivo para exercer essa atividade. Dessa forma, a universidade não via essa função como sendo uma atividade da universidade e, por isso, não contava nos relatórios de atividades dos professores. Mas, recentemente, isso foi mudado, passando a ser contabilizado nas horas trabalhadas, para fins de progressão na carreira. 
"nós trabalhávamos, não era nem contado no nosso relatório de atividade, é como se fosse, porque tem uma bolsa, um trabalho extra e trabalho que algumas pessoas fazem. Hoje eu acho que já está superado isso, não totalmente, mas superando" (Entrevistado 11).

Pode-se perceber que o curso de administração pública a distância na UFLA está a caminho da normalização, mas ainda tem muito a ser feito para que as ações passem a fazer parte da rotina da universidade.

Dessa forma, ao concluir a análise das 3 subcategorias referentes à categoria Habitualização Inovação, Estrutura e Políticas e Procedimentos - pode-se inferir que o curso de administração pública a distância na Universidade Federal de Lavras está em um estágio moderado de habitualização. Visto que o curso foi considerado uma inovação, está estruturado dentro da Universidade, mas ainda há falhas em questões de políticas e procedimentos. Adiante se inicia a análise da categoria Objetificação.

\section{Objetificação}

Dentro da categoria Objetificação, definiram-se 4 subcategorias: Monitoramento Interorganizacional, Consenso Social, Difusão da Estrutura, Presença de Champions.

Inicia-se a análise pela subcategoria monitoramento interorganizacional, para compreender se a universidade analisou como outras organizações implementaram essa estrutura e como administram atualmente.

Não se percebe na universidade uma preocupação em monitorar outras universidades, somente algumas ações individuais por parte de alguns coordenadores. Na época da implementação, existia a preocupação por parte da UAB em manter os coordenadores de curso em comunicação através de fórum de discussão. E esse era ativo, com troca de experiências e dúvidas (2 citações), mas atualmente se encontra desatualizado.

A troca de informações, hoje, se atém aos contatos pessoais realizados pelos coordenadores (5 citações), com professores conhecidos, em eventos, e essa busca de informação pode ocorrer até mesmo na leitura de artigos de experiências de outras universidades, o que demonstra a dificuldade de ocorrer isomorfismo mimético (Dimaggio \& Powel, 1983), visto que não há a pretensão por parte do grupo de analisar as outras universidades.

Analisando o contexto da educação a distância da UFLA, pode-se perceber um monitoramento dentro da instituição entre os cursos, sendo o curso de administração pública a distância uma das primeiras experiências e os demais cursos que estão sendo implementados, de certa forma aproveitam a estrutura montada para esse curso, com algumas melhorias. Continuando essa análise, parte-se para a análise da subcategoria Difusão da Estrutura.

Hoje, a universidade tem, além do curso de administração pública, mais 3 cursos de graduação a distância em funcionamento, e 1 previsto para o primeiro semestre de 2012. Por compartilharem a estrutura do Centro de Educação a Distância (7 citações), os coordenadores desse centro são responsáveis pelo fluxo de informação entre cursos. Assim sendo, os novos poderão muito se beneficiar do trabalho desenvolvido desse primeiro curso.

Dessa forma, pode-se perceber, dentro da universidade, uma alta difusão da estrutura, visto que os novos cursos foram implementados aproveitando as experiências do curso em questão, e a mesma estrutura organizacional, assim como o apoio dado pelo CEAD. A universidade começa, então, a dar valor maior para essa estrutura. A fim de poder conhecer se existe um consenso acerca desse valor, analisa-se a existência de grupos de resistência e de apoio a essa estrutura. Dessa forma, inicia-se a descrição da subcategoria Consenso Social. Parte-se do pressuposto que, quanto mais institucionalizada está uma estrutura, menor é a resistência existente e maior é o consenso a respeito do valor da estrutura (Oliver, 1991). 
A partir da análise, infere-se que não existe um consenso a respeito do valor da estrutura dentro da universidade. Do total de 11 entrevistados, 10 afirmaram não haver consenso a respeito do valor da estrutura. Afirmaram que os grupos contrários já diminuíram, mas ainda existem.

"Não, ainda tem grupos que defendem, grupo que ataca. Embora o grupo que é resistente eu vejo que ele tem diminuído, tem diminuído com o tempo" (Entrevistado 5).

Ao se falar em consenso, não se pode deixar de falar da existência de champions, que são os atores que têm interesse na estrutura e podem promover a sua difusão (Tolbert \& Zucker, 1998). Assim sendo, inicia-se a análise da quarta subcategoria - Presença de Champions. Por meio da análise das entrevistas, o CEAD (9 citações), na figura de seus coordenadores, caracteriza-se como sendo o grupo que tem interesse na estrutura, que busca a normalização, não só do curso de administração pública a distância, mas também de todos os cursos oferecidos na modalidade a distância ou semipresencial.

"Aí é o CEAD, aí é o pessoal que está junto ao CEAD. São as pessoas que realmente acreditam no processo" (Entrevistado 10).

As 4 subcategorias da categoria Objetificação indicam uma moderada objetificação, pois, mesmo existindo um grupo que trabalha em prol dessa estrutura, e ela está sendo difundida dentro da instituição, ainda não há um consenso sobre o valor dessa estrutura. O que, de acordo com Tolbert e Zucker (1998), são indicadores da fase de semi-institucionalização. O próximo passo é analisar a última fase de institucionalização, a sedimentação.

\section{Sedimentação}

A categoria Sedimentação foi analisada a partir de 3 subcategorias: Baixa Resistência, Continuidade da Estrutura e Resultados Positivos. Inicia-se a apresentação dos resultados dessa categoria a partir da subcategoria Baixa Resistência. Os entrevistados, ao serem questionados sobre a existência de resistência, de grupos opositores, reconhecem que esse grupo diminuiu com o tempo (8 citações), mas que ainda existem.

A diminuição da resistência dentro dos grupos opositores ocorreu à medida que mais pessoas foram se tornando envolvidos com essa modalidade de ensino ( 3 citações). O uso de tecnologias no ensino presencial está contribuindo para diminuir o grupo contrário (3 citações). Outro fator que também permitiu essa diminuição foi a nota dos alunos do curso piloto na avaliação do INEP (2 citações), que foi maior do que a dos alunos no ensino presencial.

"Uma coisa que foi muito boa é que, nas últimas avaliações do INEP, os estudantes a distância, na modalidade a distância, tiveram um desempenho superior aos do presencial. Então isso ajudou a minimizar muitas resistências" (Entrevistado 5).

A melhoria na operacionalização da $\mathrm{EaD}$ a partir do trabalho do CEAD também foi citado como um fator que ajudou a diminuir a oposição (3 citações). Mas, na visão de 2 entrevistados, a resistência ainda é alta. Dessa forma, pode-se perceber que ainda há resistência, mesmo que essa já tenha diminuído com o tempo. Ainda há um caminho a percorrer até que essa se torne baixa.

Outra subcategoria importante dentro da Sedimentação é a Continuidade da Estrutura, ou seja, se a estrutura está sobrevivendo através de gerações de membros da organização. Dentre os 11 entrevistados, 9 disseram que o curso de administração pública tem condições de continuar, pela forma como está estruturado, existem melhorias a serem feitas assim como em qualquer outro curso que necessita aperfeiçoar sempre.

"Então eu acho que a condição de continuidade dele no padrão que ele tem hoje, não é uma coisa que tá depondo contra a UFLA. Mas eu acho que ele pode melhorar bastante ainda” (Entrevistado 3). 
Para continuidade da estrutura, algumas questões têm que ser aperfeiçoadas. É necessário pensar-se como oferecer ensino, pesquisa e extensão nesse curso ( 2 citações). As condições dos alunos nos polos de apoio presencial precisam ser melhoradas, visto que a manutenção dos polos é de responsabilidade do município (7 citações). Uma questão, por exemplo, é o acesso à bibliografia básica do curso nos polos de apoio presencial.

Os recursos tecnológicos são um fator que ainda é deficiente (7 citações). Em um curso a distância, os recursos tecnológicos são essenciais. A estrutura física do CEAD também precisa ser ampliada (3 citações), ainda não tem uma estrutura própria. Há, além disso, uma dificuldade de contratação de pessoal devido às especificidades exigidas pela CAPES/UAB, como por exemplo, pessoal para trabalhar com elaboração de material didático (3 citações).

Outros fatores precisam ser melhorados: acompanhamento dos tutores por parte da coordenação (1 citação), parceria com o município (1 citação), cumprimento de prazos por parte dos professores (1 citação). Todos esses aspectos citados acima afetam negativamente a continuidade da estrutura e, por isso, precisam ser melhorados. Mas o grande fator que faz com que essa estrutura se torne instável é o financiamento (11 citações).

"Uma das situações que eu acho que é uma fragilidade no sistema é como eles são financiados: por projetos. A gente não tem muito uma garantia de continuidade desses cursos, uma vez que a cada ano tenta-se aprovar o projeto de financiamento, então pode haver realmente solução de continuidade que está acontecendo agora com o Administração Pública. Isso é uma fragilidade no processo porque ele acaba não se estabilizando" (Entrevistado 1).

E por estar vivendo esse momento em que a CAPES/UAB não dá indícios de que irá continuar financiando ou não, o colegiado do curso junto ao CEAD decidiram não ofertar uma nova turma em 2012. Esse momento é um momento de muita incerteza por parte das coordenações, visto que eles não sabem como proceder, por isso resolveram interromper a oferta. Não se pode falar em não oferta, visto que isso não foi citado por nenhum entrevistado, mas não se veem grandes possibilidades de continuação sem o financiamento via UAB/CAPES.

Pode-se perceber que o curso de administração pública a distância tem condições de continuar em se tratando da forma como está sendo operacionalizado. Existem melhorias a serem feitas para aperfeiçoamento do curso como, por exemplo, em infraestrutura tecnológica, fator mais citado pelos entrevistados. Mas, caso a UAB/CAPES decida não continuar com a política de financiamento desse curso, a universidade não dispõe de recursos financeiros para continuidade. Dessa forma, não se pode inferir sobre a sobrevivência do curso de administração pública a distância na instituição.

Continuando a análise, parte-se para a subcategoria Resultados Positivos. Diante do fato do curso estar no início, ter somente 4 semestres de funcionamento, a avaliação dos resultados positivos se firma na percepção dos entrevistados, ou seja, o que esperam como resultados positivos e se o curso está atendendo às expectativas. De acordo com os entrevistados, o curso tem apresentado bons resultados (11 citações). Bons resultados pelo fato de possibilitar a democratização do ensino (2 citações), o índice de evasão está entre o comum para cursos na modalidade a distância, até mesmo menor ( 2 citações), pela evolução organizacional que já teve desde o início (1 citação), por exigir bastante dos alunos (2 citações).

"Eu acho que a gente tem alcançado resultados positivos, até do ponto de vista quantitativo, a nossa evasão é menor do que muitos cursos, por conta de uma estratégia que a gente tem adotado tanto de capacitação de tutor, de intervenção mais direta com aluno, uma coisa que dá trabalho" (Entrevistado 9).

Para se inferir sobre a Sedimentação, utilizaram-se as subcategorias Continuidade da Estrutura, Baixa Resistência e Resultados Positivos. A subcategoria Baixa Resistência demonstrou que a resistência diminuiu, mas ainda é existente, fato que pode demonstrar que com o tempo a resistência pode se tornar baixa ou deixar de existir. Quanto à subcategoria Resultados Positivos, os coordenadores assumiram que o curso está tendo bons resultados, mesmo estando no segundo ano do curso e ter muitos desafios pela frente. E, por último, a subcategoria Continuidade da Estrutura. Pode- 
se perceber que o curso de administração pública a distância, na opinião dos entrevistados, tem condições de continuar em se tratando da forma como está sendo operacionalizado, mas depende completamente da política pública da UAB. Dessa forma, pode-se afirmar que o curso encontra-se em um estágio inicial da fase de sedimentação.

\section{Legitimação}

Analisando pelo pilar regulativo, o curso de administração pública a distância está legitimado, visto que opera de acordo com os requisitos legais. O curso é ofertado pela Universidade Aberta do Brasil, por meio da UFLA, e é integrante do Programa Nacional de Formação em Administração Pública (PNAP), edital n ${ }^{\circ}$ 01, de 27 de abril de 2009, atendendo aos procedimentos de adesão nele dispostos.

Quanto ao pilar normativo, os entrevistados se ativeram a responder quanto à legitimidade da educação a distância, afirmando que ainda não se pode falar sobre o curso de administração pública, visto que é muito recente. Acreditam que a sociedade ainda não legitima a educação a distância (7 citações), mas é uma questão de tempo.

Quanto ao mercado profissional, 3 citaram que o mercado legitima essa modalidade de ensino, 1 disse que não e 3 afirmaram que parte do mercado legitima, mas que ainda há grupos específicos que não legitimam. Um ponto interessante levantado pelos entrevistados 8 e 9 é o fato de o mercado acadêmico não legitimar essa modalidade.

"O mercado de trabalho, sim. O mundo acadêmico, não. O mercado de trabalho, quando você vai buscar um emprego, uma vaga, se a pessoa ver que você tem condições de desempenhar aquelas atividades, faz de maneira satisfatória, ninguém vai ficar perguntando onde você estudou, de que maneira você estudou, quem te deu aula, então acredito que o mercado de trabalho está pronto para isso" (Entrevistado 8).

Em se tratando de universidade e governo, os entrevistados acreditam que esses atores já legitimam a educação a distância, talvez como uma modalidade de ensino eficiente ou talvez como uma solução para a democratização do ensino.

O curso de administração pública a distância, especificamente a modalidade de ensino, parece que ainda não está legitimada perante os seus stakeholders. Mas, o fato da universidade ter implementado esse curso impacta positivamente a legitimidade da universidade ( 9 citações). Somente dois entrevistados tiveram uma visão contrária.

“Aí você vem com a UAB; a UFLA aderir com a UAB e está desde o início, certamente fez crescer o conceito junto ao Fernando Haddad, ao MEC, e ela está disponibilizando curso pra sociedade, os cursos UAB, os polos em vários lugares, a UFLA ficou conhecida - em Campos Gerais, um dos polos que a UFLA tem - a UFLA está em Campos Gerais, a cidade está sendo beneficiada, o prefeito estendia o tapete vermelho lá pra qualquer pessoa da UFLA, não era só pro reitor não" (Entrevistado 2).

Fato interessante: mesmo a estrutura não sendo legitimada perante os seus stakeholders, a implementação desta impacta positivamente a legitimidade da universidade.

\section{Isomorfismo}

Durante o processo de institucionalização do curso de administração pública a distância, evidenciou-se o isomorfismo coercitivo, não evidenciando isomorfismo mimético e normativo. $\mathrm{O}$ curso foi criado pela UAB já com o projeto pedagógico pronto, permitindo algumas alterações. Assim sendo, alguns aspectos relativos à estrutura administrativo-pedagógica, infraestrutura e processo de gestão acadêmico-administrativa, estrutura curricular, já estavam descritos. A UAB exerce, nesse caso, uma pressão coercitiva (Scott, 2001) ao impor uma estrutura organizacional em uma unidade subordinada, o que, de certa forma, reporta ao isomorfismo coercitivo (Dimaggio \& Powell, 1983), fazendo com que todas as universidades se assemelhem nessa estrutura. 
"Existem n modelos de arranjo tecnológico e pedagógico dentro da educação a distância; a UAB tem um modelo que, é lógico, permite determinados arranjos pedagógicos, mas é muito mais restrita à opção da universidade por isso.... eu tenho todo um arranjo que vai dizendo como é que o curso tem que funcionar" (Entrevistado 6).

Outro fato que evidencia o isomorfismo coercitivo foi o processo de disponibilização do curso pela UAB e a tomada de decisão das universidades. A UAB lançou um edital e a universidade que tivesse interesse enviava a proposta, mas, de certa forma, todas as universidades queriam ofertar esse curso, já que era uma ação legitimada pelo governo, o que as tornariam mais legitimadas perante o governo federal.

\begin{abstract}
"Então eu particularmente acredito que, quando saiu o edital, qualquer que seja do Governo Federal, inclusive editais de pesquisas, acabam direcionando as universidades a atuarem naquele sentido porque é uma fonte de recursos, é uma possibilidade de renovação, é uma possibilidade de você, digamos assim, estar dentro dos parâmetros que são valorizados com a CAPES, pelo MEC num dado momento" (Entrevistado 9).
\end{abstract}

Encerrando a análise do caso da Universidade Federal de Lavras, pode-se perceber que esse processo de institucionalização evidencia o isomorfismo coercitivo através da dependência de recursos da Universidade em relação à UAB/CAPES.

\title{
Considerações Finais
}

Utilizando como base o trabalho de Tolbert e Zucker (1998), este estudo procurou analisar as fases do processo de institucionalização do curso de administração pública a distância da UFLA, bem como as evidências de isomorfismo e legitimação. Observou-se que o curso de administração pública a distância está em estágio moderado de habitualização. Visto que o processo ainda é falho em relação a normalização das políticas e procedimentos. Da mesma forma, a fase de objetificação, que envolve a difusão da estrutura e o desenvolvimento de certo grau de consenso social a respeito do valor da estrutura, também se encontra em um estágio moderado, pois mesmo existindo um grupo que trabalha em prol dessa estrutura (os champions), e ela está sendo difundida dentro da instituição, ainda não há um consenso sobre o valor dessa estrutura. Em relação à fase de sedimentação, observa-se que ainda há grupos de resistência na UFLA, e que a continuidade da estrutura vive um momento incerto, que depende da continuação de uma política pública. E, quanto aos resultados, tiveram-se indícios de o curso estar tendo bons resultados, mas que ainda há aspectos falhos que podem impactar negativamente os resultados. Dessa forma, caracteriza-se como estando em um estágio inicial de sedimentação.

Não era a intenção desse trabalho afirmar se esse curso está ou não institucionalizado, e sim de verificar como essa nova estrutura está se institucionalizando dentro da universidade.

Outros dois aspectos importantes analisados foram o isomorfismo e a legitimação. Esse processo de institucionalização apresenta evidências de isomorfismo coercitivo através da dependência de recursos da UAB/CAPES. Esse tipo de isomorfismo resulta de pressões formais, assim como de pressões informais exercidas sobre as organizações (Machado-da-Silva et al., 2003). Essa mudança isomórfica está em conformidade com um dos preditores de DiMaggio e Powell (1983), que afirma que quanto mais centralizado é o fornecimento de recurso para uma organização, maior é a possibilidade de a organização se transformar para se assemelhar com a organização a que depende.

E, em relação à legitimidade, na opinião dos entrevistados, essa estrutura ainda não está legitimada na visão do pilar normativo, mesmo já estando legitimada na visão do pilar regulativo. Um fato interessante é que, mesmo sem ser legitimada perante aos seus stakeholders, a implementação desse curso impacta positivamente a legitimidade da universidade. 
Analisar o processo de institucionalização do curso de administração pública a distância é importante tanto para as Universidades estudadas, assim como para a Universidade Aberta do Brasil, parceiras na oferta desse curso. No âmbito da universidade, podem-se buscar informações que poderão levar à identificação dos principais problemas na visão dos atores envolvidos no processo e fornecer subsídios para propor estratégias de melhorias. No caso da UAB, esta poderá perceber as dificuldades enfrentadas pelas universidades para a continuação desse curso, podendo propor melhorias para melhor condução dessa parceria.

$\mathrm{O}$ fato de estar ligado diretamente a um programa federal gera uma instabilidade que afeta a institucionalização. Para poder melhor expressar sobre a institucionalização do curso de administração pública a distância, a política do governo deveria ser analisada. Dessa forma, para pesquisas futuras, sugere-se o estudo do PNAP, focando na institucionalização dessa política.

Percebeu-se que o processo de institucionalização dos cursos está acontecendo simultaneamente com a institucionalização da Educação a Distância na universidade. Dessa forma, sugere-se para estudos posteriores a análise do processo de institucionalização da educação a distância no Brasil.

Como limitação, este estudo descreve a realidade a partir da visão dos entrevistados. Assim, alguns aspectos importantes podem ter sido omissos, limitando o trabalho. De qualquer forma, esse trabalho não é o ponto final deste estudo, e sim o ponto de partida para pesquisas futuras que devem surgir a partir deste.

\section{Referências}

Alonso, K. M. (2010). A expansão do ensino superior no Brasil e a EAD: dinâmicas e lugares. Educação \& Sociedade, 31(113), 1319-1335. doi: 10.1590/S0101-73302010000400014

Baptista, J. (2009). Institutionalization as a process of interplay between technology and its organizational context of use. Journal of Information Technology, 24(4), 305-319. doi: 10.1057/jit.2009.15

Berger, P. L., \& Luckmann, T. (1967). The social construction of reality: a treatise its the sociology of knowledge. New York: Anchor Books.

Berger, P. L., \& Luckmann, T. (2003). A construção social da realidade (23a ed., F. de S. Fernandes, Trad.). Petrópolis: Vozes. (Obra original publicada em 1967)

Carvalho, C. A., Vieira, M. M. F., \& Goulart, S. (2005). A trajetória conservadora da teoria institucional. Revista de Administração Pública, 39(4), 849-874.

Carvalho, C. A., Vieira, M. M. F., \& Lopes, F. D. (1999, setembro). Contribuições da perspectiva institucional para análise das organizações. Anais do Encontro Nacional da Associação Nacional de Pós-Graduação e Pesquisa em Administração, Foz do Iguaçu, PR, Brasil, 23.

Dambrin, C., Lambert, C., \& Sponem, S. (2007). Control and change: analysing the process of institutionalization. Management Accounting Research, 18(2), 172-208.

Dimaggio, P. J., \& Powell, W. W. (1983). The iron cage revisited: institutional isomorphism and collective rationality in organizational fields. American Sociological Review, 48(2), 147-160. doi: $10.2307 / 2095101$

Freeman, C., \& Perez, C. (1988). Structural crises of adjustment: business cycles and investment behaviour. In G. Dosi, C. Freeman, \& R. Nelson (Eds.), Technical change and economic theory (Cap. 3, pp. 38-66). Londres: F. Pinter. 
Green, S. E., Jr., Li, Y., \& Nohria, N. (2009). Suspended in self-spun webs of significance: a rhetorical model of institutionalization and institutionally embedded agency. Academy of Management Journal, 52(1), 11-36. doi: 10.5465/amj.2009.36461725

Instituto Nacional de Estudos e Pesquisas Educacionais. (2010). Resumo técnico do censo da educação superior. Brasília: Ministério da Educação. Recuperado de http://download.inep.gov.br/educacao_superior/censo_superior/resumo_tecnico/resumo_tecnico _censo_educacao_superior_2010.pdf

Instituto Nacional de Estudos e Pesquisas Educacionais. (2011). Censo da educação superior 2010: divulgação dos principais resultados do censo da educação superior 2010. Brasília: Ministério da Educação. Recuperado de http://download.inep.gov.br/educacao_superior/censo_superior/documentos/2010/divulgacao_c enso_2010.pdf

Levine, S. S., \& Zajac, E. J. (2008, August). Institutionalization in efficient markets: the case of price bubbles. Academy of Management Proceedings, Academy of Management, Anaheim, Califórnia, USA.

Machado-da-Silva, C. L., Fonseca, V. S. da, \& Crubellate, J. M. (2005). Estrutura, agência e interpretação: elementos para uma abordagem recursiva do processo de institucionalização (1 ${ }^{\mathrm{a}}$ Edição Especial). Revista de Administração Contemporânea, 9, 9-39. doi: 10.1590/S141565552005000500002

Machado-da-Silva, C. L., Guarido, E. R., Filho, Nascimento, M. R., \& Oliveira, P. T. (2003). Institucionalização da mudança na sociedade brasileira: o papel do formalismo. In M. M. F. Vieira \& C. A. Carvalho (Orgs.), Organizações, instituições e poder no Brasil (Vol. 1, pp. 179202). Rio de Janeiro: Editora FGV.

Martins, M. A., \& Meirinhos, M. (2011). Análise das relações entre intervenientes num fórum de discussão em contexto de aprendizagem. Bragança: Instituto Politécnico de Bragança. Recuperado de https://bibliotecadigital.ipb.pt/bitstream/10198/6180/1/IETICID_15.pdf

Meyer, J. W., \& Rowan, B. (1977). Institucionalized organizations: formal structure as myth and ceremony. American Journal of Sociology, 83(2), 340-363.

Minayo, M. C. S. (2000). O desafio do conhecimento: pesquisa qualitativa em saúde (7a ed.). São Paulo: Hucitec; Rio de Janeiro: Abrasco.

Mintzberg, H. (Ed.). (2003). Criando organizações eficazes: estrutura em cinco configurações (2a ed.). São Paulo: Atlas.

Moore, M., \& Kearsley, G. (2007). Educação a distância: uma visão integrada (R. Galman, Trad.). São Paulo: Thomson Learning. (Obra original publicada em 1996)

Moran, J. M. (2009). O ensino superior a distância no Brasil. Educação e Linguagem, 12(19), 17-35.

Morrill, C. (2007). Institutional change through interstitial emergence: the growth of alternative dispute resolution in American law, 1965-1995. In W. W. Powell \& D. L. Jones (Eds.), How institutions change (pp. 1-54). Chicago: University of Chicago Press.

Novais, S. M., \& Fernandes, A. S. S. (2011). A institucionalização do ensino a distância no Brasil: o caso da graduação em administração na Universidade Federal do Rio Grande do Norte (UFRN). Revista de Ciências da Administração, 13(28), 173-201. doi: 10.5007/21758077.2011v13n29p173

Oliver, C. (1991). Strategic responses to institutional process. Academy of Management Review, 16(1), 145-179. doi: 10.5465/AMR.1991.4279002 
Owen-Smith, J. (2011). The institutionalization of expertise in university licensing. Theory and Society, 40(1), 63-94. doi: 10.1007/s11186-010-9136-y

Quinello, R. (2008). Processo de institucionalização do seis sigma em uma empresa automobilística. Revista de Administração Mackenzie, 7(3), 148-179.

Rossoni, L., \& Mendes-da-Silva, W. (2011, maio). Nos limites da legitimidade: uma análise do risco no mercado de capitais brasileiro. Anais do Encontro de Estudos em Estratégia, Porto Alegre, Rio Grande do Sul, Brasil, 5.

Scott, W. R. (1987). The adolescence of institutional theory. Administrative Science Quarterly, 32(4), 493-511. doi: $10.2307 / 2392880$

Scott, W. R. (2001). Institutions and organizations (2nd ed.). Thousand Oaks: Sage.

Selznick, P. (1971). A liderança na administração. Rio de Janeiro: Fundação Getúlio Vargas.

Suddaby, R. (2010). Challenges for institutional theory. Journal of Management Inquiry, 19(1), 14-20. doi: $10.1177 / 1056492609347564$

Tolbert, P. S., \& Zucker, L. G. (1998). A institucionalização da teoria institucional. In S. R. Clegg, C. Hardy, \& W. R. Nordy (Orgs.), Handbook de estudos organizacionais: modelos de análise e novas questões em estudos organizacionais (pp. 196-219). São Paulo: Atlas.

Universidade Federal de Lavras. (2011). Sobre a UFLA. Lavras. Recuperado de http://www.ufla.br/index.php/a-instituicao/historia.

Vilarinho, L. R. G., \& Paulino, C. L. (2010). Educação a distância no ensino superior Brasileiro: das experiências pioneiras ao sistema de rede. Revista Eletrônica de Educação, 4(1), 64-79. Recuperado de http://www.reveduc.ufscar.br/index.php/reveduc/article/viewFile/116/82

Yin, R. K. (1994). Case study research. London: Sage.

Zucker, L. G. (1977). The role of institutionalization in cultural persistence. American Sociology Review, 42(5), 726-743.

Zucker, L. G. (1988). Where do institutional patterns come from?: organizations as actors in social systems. In G. Lynne \& L. G. Zucker (Eds.), Institutional patterns and organizations: culture and environment (pp. 23-49). Cambridge: Ballinger. 